\title{
The current state of prenatal detection of genetic conditions in congenital heart defects
}

\author{
Tina O. Findley ${ }^{1}$, Hope Northrup ${ }^{2}$ \\ ${ }^{1}$ Division of Neonatal-Perinatal Medicine, Department of Pediatrics, McGovern Medical School, University of Texas Health Science Center at \\ Houston, Houston, TX, USA; ${ }^{2}$ Division of Medical Genetics, Department of Pediatrics, McGovern Medical School, University of Texas Health \\ Science Center at Houston, Houston, TX, USA \\ Contributions: (I) Conception and design: TO Findley; (II) Administrative support: None; (III) Provision of study materials or patients: None; (IV) \\ Collection and assembly of data: None; (V) Data analysis and interpretation: None; (VI) Manuscript writing: All authors; (VII) Final approval of \\ manuscript: All authors. \\ Correspondence to: Tina O. Findley, MD. Division of Neonatal-Perinatal Medicine, Department of Pediatrics, McGovern Medical School, University \\ of Texas Health Science Center at Houston, 6431 Fannin Street, MSB 3.218, Houston, Texas 77030, USA. Email: Tina.O.Findley@uth.tmc.edu.
}

\begin{abstract}
The incidence of congenital heart defect (CHD) has increased over the past fifty years, partly attributed to routine fetal anatomical examination by sonography during obstetric care and improvements in ultrasound technology and technique. Fetal findings on ultrasound in addition to maternal biomarkers are the backbone of first- and second-trimester screening for common genetic conditions, namely aneuploidy. Since the introduction of non-invasive prenatal testing (NIPT) using next-generation sequencing to sequence cell-free fetal DNA, the detection rate of common trisomies as well as sex chromosomal aneuploidies have markedly increased. As the use of NIPT continues to broaden, the best means of incorporating NIPT into prenatal care is less clear and complicated by misunderstanding of the limitations and non-diagnostic role of NIPT by clinicians and families. In other advancements in prenatal genetic testing, recommendations on the role of chromosomal microarray (CMA) for prenatal diagnosis has led to its increasing use to identify genetic conditions in fetuses diagnosed with CHD. Lastly, as whole exome sequencing (WES) becomes more available and affordable, the next clinical application of next-generation sequencing in prenatal diagnostic testing is on the horizon. While newer genetic tests may provide answers in terms of genetic diagnosis, even more questions will likely ensue for clinicians, researchers, and parents. The objective of this review is to provide the perspective of the evolution of maternal and fetal obstetric care against the backdrop of advancing genetic technology and its impact on families and clinicians.
\end{abstract}

Keywords: Congenital heart defect (CHD); prenatal; genetic

Submitted Oct 01, 2020. Accepted for publication Nov 05, 2020.

doi: $10.21037 / \mathrm{tp}-20-315$

View this article at: http://dx.doi.org/10.21037/tp-20-315

\section{Introduction}

Routine prenatal ultrasound screening and improvements in ultrasound technology and technique have increased prenatal detection of congenital heart defect (CHD) $(1,2)$. Mild lesions have been the main contributors to the increase in prevalence, e.g., septal defects, while the rate of severe lesions has remained stable over the past fifty years $(3,4)$. Contributors to the rise in incidence include greater use of echocardiography, improvement in echocardiographic techniques performed prenatally, and availability of healthcare resources. The earliest identifiable genetic cause of CHD was aneuploidy (e.g., trisomies 13, 18, 21), and fetal ultrasound findings and maternal serum biomarkers screening for aneuploidy has been a standard component of prenatal obstetric care. Due to earlier detection of fetal anomalies on ultrasound and broader availability of screening and diagnostic genetic tests prenatally, testing 
has shifted earlier to the antenatal period for many of these patients. In this review, we will discuss the capabilities and limitations of current methods to detect prenatal genetic conditions associated with CHD, the latest advancements and recommendations for newer genetic tests, and their impact on patient outcomes and parental decision-making. We will not discuss all of the genetic conditions associated with CHD, but rather, focus on key syndromes as a means of highlighting the advantages and disadvantages of various screening and testing methods.

CHD comprises a spectrum of disease involving structural malformations of the heart and/or great vessels. Lesions commonly excluded in the literature include those found frequently in fetuses (i.e., patent foramen ovale and patent ductus arteriosus), lesions difficult to detect prenatally (i.e., bicuspid aortic valve), aortopathies, cardiomyopathies, and arrhythmias $(5,6)$. There are challenges in defining and categorizing cardiac phenotypes. For example, complex, non-heterotaxy CHD made up of any combination of defects may often be grouped in a single, separate category with widely variable phenotypes (5). In addition, when discussing prenatally-detected CHD, one should also consider the limitations in screening ultrasound technique resulting in better detection of anomalies with an abnormal four-chamber view, while abnormalities of the outflow tract and great arteries are more likely to be missed $(7,8)$. This may result in over-representation of lesions with malformed chambers and an under-representation of outflow tract anomalies in prenatal studies.

\section{Maternal antenatal screening}

Standard obstetrical practice includes maternal serum screening and detection of ultrasound findings suggestive of fetal aneuploidy for all pregnancies. While advanced maternal age of 35 years and above was previously an indication for screening for fetal aneuploidy, the latest recommendations by the American College of Medical Genetics and Genomics (ACMG) and American College of Obstetricians and Gynecologists (ACOG) suggest offering screening to all expectant mothers regardless of age $(9,10)$. All prenatal screening methods are voluntary and may be deferred by women who decline genetic information on their fetus. Discovery of any fetal anomaly including CHD may increase the clinician's suspicion for a genetic condition and prompt further screening. A separate review in this special issue will address prenatal detection of CHD by ultrasound, therefore we will only mention that certain lesions are more readily identified on anatomical scanning compared to other lesions so may be disproportionately represented in prenatal genetic studies.

\section{First trimester screening}

A combination of nuchal translucency (NT) thickness and two maternal biomarkers, pregnancy-associated plasma protein A (PAPP-A) and human chorionic gonadotropin (hCG), screens for trisomy 21 (Down syndrome) and trisomy 18 (Edwards syndrome) in the first trimester. Performed between 11 and 13 6/7 weeks' gestation, NT screening measures the width of the skin behind the fetus' neck and may be increased due to the subcutaneous collection of fluid often associated with aneuploidies. As an independent test, NT screening alone detects approximately $50-70 \%$ of trisomy 21 in the prenatal period. The addition of PAPP-A and hCG levels collected between 9 and 13 $6 / 7$ weeks' gestation improves detection of trisomy 21 by approximately $90 \%(11,12)$. Abnormal results of decreased PAPP-A and elevated hCG levels occur in trisomy 21 , whereas both biomarkers are reduced in trisomy 18. False positives can occur due to incorrect gestational dates and multi-fetal gestation, while factors influencing the sensitivity of NT screening to detect aneuploidies include the presence of cystic hygroma and other genetic conditions associated with increased NT. Increased NT ( $\geq 3.5 \mathrm{~mm})$ alone has also been associated with critical CHD without chromosomal abnormalities although it has poor sensitivity in cases of isolated CHD (13-15).

\section{Non-invasive prenatal testing (NIPT): uses and implications}

Due to the rapidly evolving knowledge related to NIPT and its substantial impact on prenatal genetic testing, a significant portion of this review will be dedicated to discussing past studies and current updates. Advances in genomic technology using massive parallel shotgun sequencing led to the development of NIPT, a screen identifying cell-free fetal DNA sequences originating from placental cells and circulating in maternal blood (16). During the initial prospective trials, NIPT testing in highrisk women demonstrated $100 \%$ sensitivity and greater than $99 \%$ specificity for the detection of trisomy 21 (17-19). In these trials, NIPT also had excellent sensitivity and specificity for trisomy 18 (97\% and 100\%, respectively) and trisomy 13 (Patau syndrome) (79\% and 100\%, respectively). Nicolaides et al. studied the performance of NIPT in the 
general population of average risk women and found that NIPT maintained its accuracy in detecting trisomies 21 and 18 (20). In two large prospective, blinded, multi-center trials, pregnant women of all risk (average and high risk) were randomized to receive NIPT or standard first trimester screening. Results showed NIPT had higher sensitivity and positive predictive value (PPV) in detecting trisomy 21 (NIPT vs. standard screening, PPV 45.5-80.9\% vs. $3.4-4.2 \%$, respectively) (21,22). A meta-analysis demonstrated that NIPT had excellent PPV for aneuploidies in high-risk women $(92 \%, 84 \%$, and $87 \%$ for trisomy 21 , 18 , and 13 , respectively). However, due to the relatively low prevalence of aneuploidy in the general obstetric population of average risk, PPV were lower $(82 \%, 37 \%$, and $49 \%$ for trisomy 21,18 , and 13 , respectively) resulting in a higher rate of false negatives (23). The consistent message from many studies has been while NIPT is very accurate in detecting trisomies 21 and 18, and less accurate in detecting trisomy 13, NIPT should only be utilized as a screening test for aneuploidy and cannot replace invasive diagnostic tests $(23,24)$.

How best to incorporate NIPT into routine prenatal care has been debatable ever since its application in the clinical setting. Like any of the prenatal screening tests, NIPT is voluntary and can be performed as early as 9 to 10 weeks' gestation and up to term gestation. In addition, it is a more expensive test that patients may need to pay out-of-pocket for based on their insurance provider. While NIPT is widely covered by commercial plans for highrisk women, not all insurance providers cover average risk women, and currently some state Medicaid programs do not cover NIPT for women of any risk (25). NIPT has a lower false positive rate compared to NT measurement with maternal biomarkers resulting in fewer invasive diagnostic testing. However, the low prevalence of trisomy 21 means many average risk women ( 1 in 1,868) would need NIPT testing to detect one case of fetal trisomy 21 following a negative routine first-trimester screen (22). Additionally, pretest counseling is recommended to explain the advantages and limitations of NIPT. When a patient has a "screen-positive" result, posttest counseling is strongly recommended with possible referral to a medical geneticist or certified genetics counselor to discuss the need for prenatal diagnostic testing by chorionic villus sampling (CVS) or amniocentesis or postnatal genetic testing to confirm the diagnosis (26). Emphasis on the role of NIPT as a screening tool to patients is paramount, as is the importance of diagnostic testing prior to any consideration by the family to terminate the pregnancy. Diagnostic testing, whether performed prenatally or postnatally, will also provide information on the type of chromosomal abnormality (i.e., non-balanced translocation or Robertsonian translocation in the case of trisomy 21) to better inform parents of recurrence risk, as the latter form is inheritable.

As more women opt for NIPT and testing in the general population broadens, better understanding of the significance of certain results is also emerging. For example, expectant parents of average risk may request early NIPT to learn the biological sex of their child before the routine anatomical scan in the second trimester when external genitalia can be differentiated on fetal sonography. As a consequence, inadvertent discovery of aneuploidies including SCA may be discovered on NIPT. While detection of 45,X (Turner syndrome) was shown to be very accurate in high-risk women (sensitivity and specificity of $93.8 \%$ and $99.8 \%$, respectively), incidences of false positives can occur due to biological factors including maternal or placental mosaicism, maternal malignancy, and a demise of a twin (18,27-30). In addition to 45,X, other detectable SCA include 47,XXX (Triple X syndrome), 47,XXY (Klinefelter syndrome), and 47,XYY (Jacob's syndrome). There is also the possibility of inconclusive results if a sufficient number of fetal cells is unobtainable. Any unexpected result may be distressing to the parents and require additional followup counseling and recommendations for further diagnostic testing. Whether NIPT will ultimately avoid or lead to more invasive diagnostic testing is still being explored $(31,32)$. To date, the ACMG and ACOG have produced updated NIPT guidelines broadening inclusion of average risk women $(10,26)$. As obstetric practice evolves, an increase in the use of NIPT in the general population will likely occur. Due to the timing of NIPT, screen-positive results in the first trimester will also influence further investigation including detailed fetal sonography and fetal echocardiography to evaluate for any anomalies including CHD due to the higher incidence of structural anomalies associated with common aneuploidies and SCA. Whether expanded NIPT utilization results in improved detection of $\mathrm{CHD}$ will need investigation in the future.

\section{Invasive prenatal testing: chorionic villus sampling and amniocentesis}

All of the screening tests discussed at this point recommend following abnormal results with the option of invasive diagnostic testing by CVS or amniocentesis. While amniocentesis occurs during the second trimester, it will 
be discussed here together with CVS. CVS is performed between 10 and 13 weeks' gestation and involves an ultrasound-guided procedure to collect chorionic villi cells from the placenta through either a transcervical (more common method) or transabdominal approach. Amniocentesis, performed between 14 and 20 weeks' gestation, is an ultrasound-guided procedure using a needle to enter the amniotic sac and remove amniotic fluid. The amniotic fluid contains cells shed by the fetus and so can be used for genetic testing. Samples from both procedures are sent for genetic evaluation based on the suspected diagnosis. For example, in the case of an NIPT result that is "screen positive" for trisomy 21, karyotype analysis would be the confirmatory test of choice. The different types of diagnostic genetic tests will be discussed later in the review in greater detail.

If indications for invasive diagnostic testing present in the first trimester, CVS can be performed. One of the advantages of CVS is the opportunity to receive a diagnosis earlier in the pregnancy allowing for more management options. Risks of the procedures are rare but significant, with a meta-analysis showing a procedure-related risk of miscarriage of $0.20 \%$ with CVS and a procedure-related risk of miscarriage of $0.30 \%$ with amniocentesis (33). Rarer complications with CVS include limb-reduction defects, and milder complications involve vaginal spotting and amniotic fluid leakage. Due to these risks, parents may defer prenatal testing and wait for confirmation after the birth of their child. Beginning in 2001, prenatal serum and ultrasound screening for trisomy 21 resulted in a decline in the rates of invasive diagnostic testing, suggesting that lower rates of false positives contributed to a reduction in invasive procedures $(34,35)$. Conversely, all pregnant women may be offered prenatal screening or diagnostic testing for aneuploidy, meaning a woman may opt for invasive diagnostic testing regardless of screening results $(9,36)$.

\section{Second trimester screening}

The quadruple marker test, also known as the quad screen, is a prenatal screen performed in the second trimester of pregnancy to screen for aneuploidy, neural tube defects, and abdominal wall defects. Maternal biomarkers are collected between 15 and 18 weeks' gestation (can be up to $226 / 7$ weeks' gestation) and consist of alpha-fetoprotein (AFP), hCG, unconjugated estriol $\left(\mathrm{uE}_{3}\right)$, and dimeric inhibin A. Findings of low AFP and $\mathrm{uE} 3$ with elevated hCG and inhibin A are seen in most cases of trisomy 21. In cases of trisomy 18, AFP, hCG, and $\mathrm{uE} 3$ are lower than normal. The test was formerly known as "the triple test" before the addition of inhibin A. The quad screen has replaced the triple screen as the test of choice in the second trimester, favored for its higher sensitivity and lower false-positive rate (34). When used as a stand-alone screen in all women, the quad screen has an $88 \%$ detection rate for trisomy 21 , improving to $96 \%$ when integrated with first-trimester measurements (11). The quad screen is not a reliable test for other types of aneuploidy, and inaccurate results can occur with multiple gestation and inaccurate gestational dates.

\section{Detection of fetal anomalies by ultrasonographic screening}

Since its introduction in the 1960 s, innovations in ultrasound technology and techniques have improved the capability to delineate fetal anatomy and identify early indicators of congenital anomalies. Fetal sonography during the first trimester, routinely performed to estimate gestational age, evaluate number of fetuses, and measure NT, can also detect severe malformations such as anencephaly, omphalocele, and limb anomalies. For CHD, detection rates are roughly $50 \%$ in the first trimester (37-39). It is currently part of routine prenatal care in resource-abundant countries to perform anatomical ultrasound of the fetus during the second trimester, typically between 18 and 22 weeks' gestation. While the anatomical ultrasound can uncover more $\mathrm{CHD}$, detection rates vary widely (40). This review will focus on sonographic findings that may prompt additional genetic testing.

The detection rate of anomalies by anatomical scanning in the second trimester approximates $60 \%$ but widely varies based on experience of the ultrasonographer, body-mass index of the woman, patient population included in the study (e.g., tertiary $v s$. non-tertiary center), and severity of the anomaly (41). Major anomalies associated with aneuploidy typically visualized on ultrasound include CHD, omphalocele, and cleft lip-palate. In contrast, non-specific sonographic markers, also known as "soft markers," may be variants of normal but also associated with aneuploidy. Examples of more significant soft markers include NT (described above); absent nasal bone (trisomy 21); hyperechoic bowel (trisomy 21 and 18); shortened limbs (trisomy 21 and 18); and in-utero growth restriction (trisomy 18 and 13) (31,42-44). Many other soft markers have been described associated with fetal aneuploidy, and interpretation of isolated soft markers presents a challenge 
to the obstetrician. The genetic sonogram, using calculated likelihood ratios for isolated soft markers and maternal age, has been shown to improve detection of trisomy 21 by approximately $10 \%$ when risk is modified following the results of an abnormal quad screen (45). However, detection of soft markers after a low-risk quad screen is unlikely to be attributable to aneuploidy, and it is controversial whether such findings should be shared with women as it may raise undue alarm $(31,44)$. Furthermore, due to its inferior performance compared to the NIPT, a genetic sonogram is not recommended following the result of a normal NIPT (46). Still, incorporation of NIPT into routine prenatal care will likely influence indications for anatomical scanning and the degree of suspicion for major and minor anomalies. While a normal NIPT may be reassuring, it cannot replace a detailed anatomical scan as part of the routine prenatal care.

An abnormal quad screen with sonographic findings associated with aneuploidy, a screen-positive NIPT, major structural anomalies detected on anatomical scan, a woman at high-risk for genetic anomalies, or patient request, are all indications for further invasive diagnostic testing. However, the window of opportunity for CVS testing has passed in the second trimester so amniocentesis would be the only available prenatal option. NIPT as an alternative to invasive diagnostic testing following an abnormal anatomical sonographic examination should be discouraged, as NIPT is inferior to diagnostic genetic tests, screens only for aneuploidy, and may delay diagnosis (47). If parents defer amniocentesis, diagnosis can be confirmed after delivery.

\section{Genetic evaluation for fetal CHD}

Aneuploidy was the first identifiable genetic condition associated with CHD, with cardiac anomalies in "mongolism" first reported as early as the 1920s (48). Subsequently, what we know now as trisomy 21 was first recognized as a cytogenetic abnormality in the late 1950s (49). Considerable progress made in medical knowledge coupled with innovation in genetic testing has expanded the identification of syndromic causes for CHD in approximately $20 \%$ to $30 \%$ of patients. Genetic conditions associated with CHD are comprised of aneuploidies in $9 \%$ to $18 \%$, single-gene disorders in $3 \%$ to $5 \%$, and pathogenic copy number variants (CNVs) in $3 \%$ to $25 \%$ (50-53). While most identified genetic causes are de novo, the role of genetics in CHD is further supported by reports of higher risk of recurrence in families compared with the population (54), increased occurrences in consanguinity (55), and Mendelian, or inherited, forms of CHD in 1.8\% (56). For example, inherited point mutations involving cardiac transcription factors (e.g., NKX2.5, ZIC3) and signaling molecules (e.g., NOTCH1) have been shown to cause CHD (53). Adding complexity to the genetics of CHD is the incomplete penetrance and variable expressivity of certain genotypes, resulting in a spectrum of phenotypes (57). Hence, genetic testing of parents following an identified genetic cause in the offspring will help identify cases of inheritance even if the parents do not exhibit the phenotype. However, most cases of CHD have no clearly identified cause and may be attributable to gene-environment interactions. Examples of environmental risk factors known to contribute to CHD are maternal pregestational diabetes, teratogens during pregnancy such as tobacco exposure and retinoic acid, advanced maternal age, and infection (58).

The primary goal of prenatal genetic testing is to help identify known genetic causes of CHD. Selection of the best type of genetic test for diagnosis may be guided by the presence of syndromic findings in the fetus and/or anatomical anomalies. Advancements in genetic technology have resulted in the rapid adoption of newer genetic tests in the clinical setting that has impacted traditional prenatal care as demonstrated by NIPT discussed above. As next-generation sequencing technology progresses, tests currently used in population research studies may soon join the arsenal of prenatal genetic diagnostic tests.

\section{Syndromic CHD: identification of aneuploidy}

The first- and second-trimester screening options best target detection of aneuploidies, therefore karyotype analysis is the most commonly performed genetic test performed on fetal cells obtained by CVS or amniocentesis. Karyotyping is the gold standard for evaluating any aneuploidy including SCA. It involves gross examination of the chromosomes under microscopy and identifying differences in the appearance suggestive of a large chromosomal rearrangement (e.g., large deletions and duplications, translocation, inversion), or aberrances from the expected pair of chromosomes (i.e., monosomy, trisomy, and triploidy). Due to the involvement of a large number of genes in aneuploidy, the phenotype has broad range of effects in various body systems. For example, chromosome 21 is comprised of 200 to 300 genes, and the classic phenotype of trisomy 21 has features including distinct facies, intellectual disability, distinct personality, 
hypotonia, blood disorders, and hypothyroidism (59). A limitation of karyotype is the 7-14 days for turnaround of results as cells need to be in metaphase just prior to cell division for analysis.

\section{Syndromic CHD: identification of sex chromosome aneuploidy}

Prenatal karyotyping has improved the prenatal diagnosis of SCA, whether performed due to suspicious prenatal findings or detected incidentally (60). One example of SCA, 45,X, is due to the loss of an $\mathrm{X}$ chromosome. Made up of 800 to 900 genes, its loss explains the high rate of miscarriage, estimated to be $99 \%$ (61). In contrast, the majority of viable livebirths exhibit mosaicism $(45, \mathrm{X} / 46, \mathrm{XX})$, and the typical phenotype can range from normal to relatively mild in the newborn period, with additional features of short stature and infertility presenting later in life (62). Maternal quad screen suggestive of 45,X consists of elevated hCG and inhibin A with slightly lower levels of $\mathrm{aFP}_{\mathrm{F}}$ and $\mathrm{uE}_{3}$. However, unlike the common trisomies, maternal serum biomarkers and anatomical scanning are not accurate in detecting SCA, nor are they associated with advanced maternal age (63). The affected fetus may exhibit sonographic findings suggestive of the syndrome such as cystic hygroma, increased NT, non-immune hydrops, renal anomalies, and coarctation of the aorta, a cardiac lesion commonly associated with $45, \mathrm{X}$ (as is bicuspid aortic valve but it is more difficult to detect on fetal echocardiogram) (60). These findings are non-specific and isolated fetal sonographic findings may not trigger suspicion for an underlying genetic condition to prompt further work-up. Predictions of the phenotype based on the results of prenatal karyotype positive for $45, \mathrm{X}$ are difficult, and in the case of a normal fetal sonographic examination and incidental karyotype, a milder phenotype is more likely. Unique to cases of $45, \mathrm{X}$, postnatal confirmation is important due its milder phenotype and frequent cases of mosaicism requiring 20 to 30-cell analysis. Additional studies may be warranted to screen for occult $\mathrm{Y}$ chromosome mosaicism or ring chromosome mosaicism for future prognostication (62).

Since the increasing popularity of NIPT in prenatal screening, particularly for expectant parents interested in identification of the sex earlier in the pregnancy, the rate of pregnancies diagnosed with SCA has increased. In a meta-analysis, the detection rate for $45, \mathrm{X}$ and other non$45, \mathrm{X}$ SCA on NIPT has been reported to be $90 \%$ and $93 \%$, respectively (64). False positives may occur due to factors such as confined placental mosaicism, maternal source of circulating $45, \mathrm{X}$ related to an age-related loss of $\mathrm{X}$ chromosome, and maternal malignancy $(27,65)$. For these reasons, screen-positive results for SCA still require prenatal or postnatal confirmation.

\section{Syndromic CHD: identification of copy number variants $(C N V s)$}

CNVs are deletions or duplications of DNA sequences and are common in normal individuals, found in $4.8 \%$ to $9.5 \%$ of the human genome in the reference population (66). In large case-control population studies, de novo and rare CNV (found in less than $1 \%$ of the population) predicted to be deleterious to protein function are more likely to be associated with rare diseases and birth defects such as CHD due to negative (or natural) selection. Large $\mathrm{CNV}$ in protein-coding regions impact multiple genes and typically cause broader phenotypic effects, and deletions are typically more deleterious than duplications (51). The clinical genetic tests most sensitive for CNV are fluorescence in situ hybridization (FISH), targeting specific regions of interest, and chromosomal microarray (CMA), a genome-wide approach (also known as array comparative genomic hybridization). FISH utilizes fluorescent-labeled probes complementary to the regions of interest and is used prenatally for the rapid diagnosis (in 24-48 hours) of trisomies, gender, or specific deletions or duplications of at least $4 \mathrm{Mb}$ (67). Important limitations of FISH are the need for clinical suspicion of a specific genetic condition and the potential to miss microdeletions.

The most common microdeletion, 22q11.2 deletion syndrome, encompasses DiGeorge syndrome, velocardiofacial syndrome, and Takao conotruncal anomaly face syndrome. Most cases are de novo, but may be inherited in approximately $15 \%$ of cases (68). Notable about this genetic condition is the broad spectrum of phenotypes due to variable expressivity, or the degree a genotype is phenotypically expressed, ranging from no visible phenotype to stillbirth in the most severe manifestation $(57,69)$. The characteristic phenotype of $22 \mathrm{q} 11.2$ deletion has been well-studied and includes CHD in $75 \%$ to $80 \%$, palatal abnormalities, hypocalcemia from hypoparathyroidism, immunodeficiency from thymic aplasia or hypoplasia, and neurodevelopmental impairment $(53,70)$. It has been suggested that certain conotruncal and arch anomalies should prompt prenatal testing for $22 \mathrm{q} 11.2$ deletion including Tetralogy of Fallot, interrupted aortic arch type $\mathrm{B}$, truncus arteriosus, isolated aortic arch anomalies, and 
pulmonary atresia with ventricular septal defect and major aortopulmonary collateral arteries (MAPCAs) (57). While FISH can capture as many as $96 \%$ of $22 \mathrm{q} 11.2$ deletion cases, in cases of microdeletion too small for detection by FISH, CMA will be required for diagnosis (68). Lastly, the underlying limitation of population studies for $22 \mathrm{q} 11.2$ deletion syndrome is the likelihood of underreporting due to undiagnosed cases with normal to mild phenotype, and likewise, CHD patients who do not receive genetic testing will go undetected (70).

CMA is becoming a commonly used prenatal diagnostic tool in pregnancies affected by fetal anomalies and may be performed following a normal FISH or as a first-line test if no syndromic condition is apparent. A technique that utilizes molecular karyotyping, DNA samples are labeled with fluorochromes and undergo hybridization on a chip, and patient and control DNA are compared with abnormal ratios between the two indicating CNV (71). CMA can identify CNV as well as aneuploidies, but the advantage of CMA over karyotype and FISH is its greater diagnostic yield due to its ability to detect microdeletions and microduplications across the entire genome and relatively prompt turnaround within 7 days $(72,73)$. A metaanalysis of CMA testing on fetuses with CHD showed CMA increased diagnostic yield by $7 \%$ following a normal karyotype and 22q11-targeted FISH (74). One disadvantage of CMA is its inability to detect balanced chromosomal rearrangements, uniparental disomy, and mosaicism (75). In addition, clinicians must be aware that CMA platforms differ in probe coverage and performance of the platform and may miss certain types of mutations or microdeletions too small for detection (73).

As indications for CMA use in prenatal testing continue to expand, discovery and interpretation of $\mathrm{CNV}$ will continue to be challenging, particularly in counseling families. Standards were established to help evaluate the significance of a CNV and its potential association with a disease, changing the classification of $\mathrm{CNV}$ from a threetiered (pathogenic, variant of uncertain significance or VUS, and benign) to a five-tiered system with a scoring system for pathogenicity. The five tiers are pathogenic, likely pathogenic, VUS, likely benign, and benign $(76,77)$. When results are reported, families may not understand the implications of a variant's significance, particularly VUS, causing parental confusion and anxiety. One of the key responsibilities of posttest counseling is to explain the results of a CMA report, particularly when pathogenic variants unrelated to the diagnosis of concern are reported.

\section{Non-syndromic CHD with other anomalies}

While some of the more common syndromes have distinct clinical findings and excellent screening tests for prenatal detection, the vast majority of genetic conditions are not easily distinguishable by sonographic examination. Structural anomalies are an indication to offer diagnostic genetic testing due to the increased likelihood of genetic disorder $(36,78)$. In cases of fetuses affected by multiple major anomalies, CMA performed following a normal karyotype or FISH have been reported to identify clinically significant $\mathrm{CNV}$ in $10 \%$ to $15 \%$ of cases (79-81). Some studies have put forth recommendations that CMA replace standard karyotype or FISH in prenatal diagnostic testing due to its higher diagnostic yield $(74,82,83)$. However, professional societies including ACMG and ACOG recommend a targeted approach, where if the structural anomaly is suggestive of aneuploidy, karyotype analysis with or without FISH may be offered prior to CMA $(36,78)$.

Various studies have studied the diagnostic yield and utility of prenatal and postnatal CMA testing for all types of CHD excluding aneuploidies. Challenges in interpreting these studies include discrepancies in the definition of a clinically significant variant (namely inclusion or exclusion of VUS); the types of cardiac lesions included; platforms used for analysis; and contending with pathogenic variants not known to be a genetic contributor of CHD (although these are often included in calculating diagnostic yield of CMA). Focusing on studies conducted during the prenatal period for the purposes of this review, the largest prospective prenatal study to date by Wang et al. $(\mathrm{n}=602)$ reported an overall diagnostic rate (pathogenic $\mathrm{CNV}$ only) of $20.8 \%$ in fetal CHD with higher rates in fetuses with extracardiac anomalies compared to isolated CHD (35.9\% vs. $14.3 \%$, respectively) (83). This is similar to two other smaller prospective studies reporting overall diagnostic rates of $18.3 \%$ to $20.8 \%(84,85)$. In other studies that evaluated the diagnostic yield of CMA following a normal karyotype and/or FISH, the diagnostic yield was more discrepant (6.6\% to $33.8 \%$ ) (86-89). A large retrospective study by van Nisselrooij et al. reported a diagnostic yield of $15.6 \%$ in all fetal CHD (28.7\% in CHD with extracardiac anomalies, $11.6 \%$ in isolated CHD) (90).

There has been considerable interest in the significance in pathogenic CNV discovered in CHD, and case-control studies have consistently shown a higher incidence of rare and de novo pathogenic CNV in CHD patients compared to controls (6). Studies have also investigated the likelihood of 
different outcomes in growth, neurocognitive delays (91), transplant-free survival (92), and survival (93) in CHD patients with pathogenic $\mathrm{CNV}$ compared to those CHD patients with none identified. We are far from accurately prognosticating long-term outcomes based on the identification of pathogenic CNV alone, particularly in the prenatal period. However, as more CMA testing is performed and our knowledge of clinically significant $\mathrm{CNV}$ and associated phenotypes grows, the ability to interpret variants and identify new genotype-phenotype associations will improve and how to best responsibly provide such information to patients will continue to evolve.

\section{Single gene variants: gene panels and beyond}

A small subset of CHD are associated with single gene disorders that are undetectable by FISH, karyotype, or CMA. Single nucleotide polymorphisms, or SNPs, occur when a nucleotide is replaced by another nucleotide different from a "reference population" representative of a healthy individual. In order for a SNP to be significant it must be rare (found in less than $1 \%$ of the population), cause a change in an amino acid, splice site, or result in a STOP codon, thus predicted to change the structure or function of a protein. Insertions or deletions, or indels, resulting in frameshift mutations are considered deleterious for the same reasons. In CHD the vast majority of single gene disorders are de novo, however Noonan syndrome is a syndrome included in a group of autosomal dominant disorders (e.g., cardiofaciocutaneous syndrome, Costello syndrome) known collectively as RASopathies. RASopathies, named for the involvement of various genes in the RAS-mitogen-activated protein kinase (RAS/MAPK pathway), share features of CHD, developmental delay, and physical dysmorphisms (94). In Noonan syndrome, missense mutations in PTPN11 account for approximately half of patients with Noonan syndrome and have been associated with pulmonary valve stenosis (95). RAF1 mutations causing Noonan syndrome have also been associated with hypertrophic cardiomyopathy (96). Clinical diagnosis is challenging due to a heterogeneous phenotype and even more challenging in the prenatal period but affected fetuses may present with CHD, polyhydramnios, increased NT or cystic hygroma, pleural effusion, or hydrops fetalis $(94,97)$. In pregnancies with increased NT (at least $3 \mathrm{~mm}$ ) where aneuploidy has been ruled out, Noonan syndrome could be considered, as it is the most common single gene disordered associated with NT (98). Overall, fetal sonographic findings for Noonan syndrome are non-specific and make diagnostic discovery challenging $(99,100)$. Targeted gene panels are available and include multiple genes of interest, for example genes in the RAS/MAPK pathway that have been associated with RASopathies. If guided by clinical suspicion, targeted gene testing is cheaper with quicker turnaround of results.

The technology of next-generation sequencing is already changing the landscape of prenatal screening and detection of genetic conditions as shown with NIPT. As the technology advances, its use in the clinical setting will continue to grow (101). Whole exome sequencing (WES), the method for rapidly sequencing the proteincoding portion of the genome in parallel, is currently being explored in the prenatal setting. In one study, a small cohort of fetal CHD ( $n=44)$ with normal karyotype and CMA results received targeted next-generation sequencing comprised of a panel of $77 \mathrm{CHD}$-associated genes. CHDrelated pathogenic variants were detected in $14 \%$ of fetuses with half of pathogenic variants related to syndromes without a prenatal phenotype (102). In two large prospective studies, WES was performed on fetuses with structural anomalies found on ultrasound after normal karyotype and/ or CMA. Diagnostic genetics variants were identified in $8.5 \%$ to $10 \%$ of the study population, and $5 \%$ to $11.1 \%$ of fetuses with CHD. Rates were higher if multiple anomalies were present $(15.4 \%$ to $19 \%)$ and even higher if at least three anomalies were present (up to $35 \%)(103,104)$. Potential ethical issues arose in the studies involving the decision to not report inheritable disorders unrelated to the condition of interest and pathogenic variants predictive of adult disease. Disadvantages of WES include the cost as well as the longer turnaround for results of three to eight weeks, but both of these issues are expected to improve over time $(102,103)$. While WES is generally accepted as useful for prenatal diagnosis by the medical genetics community, the role of WES in the prenatal period is unique with controversy and contention related to reporting of "actionable results" (results that have preventative measure and/or treatment) and incidental findings to families (105).

\section{The impact of prenatal diagnosis on the family}

All families expect the good news of a healthy pregnancy, so the diagnosis of a CHD coupled with the discovery of a genetic condition is unexpected and causes much grief and distress to the parents $(106,107)$. After careful 
multi-disciplinary counseling by geneticists, cardiologists, cardiothoracic surgeons, and neonatologists, parents need as much information as possible to make the best-informed decision for their family. For severe and complex CHD, the diagnosis comes with discussions of surgical options and risks of post-surgical morbidity and mortality. While most parents pursue full medical treatment, the diagnosis of a genetic condition or severe CHD increases the likelihood of termination of pregnancy or decision to withhold medical treatment $(108,109)$. This is especially the case of a trisomy 18 or 13 diagnosis, both lethal genetic conditions with shortened expected lifespans (110). However, most centers in the United States have performed cardiac surgical interventions on children with trisomy 18 or 13 , most commonly for ventricular septal defect $(111,112)$. Ethical considerations regarding medical and surgical options and counseling of families following a prenatal diagnosis are covered in more detail in two separate reviews in this special issue $(113,114)$.

Importantly, advances in medical and surgical care have resulted in better long-term outcomes, compelling families to pursue of medical treatment regardless of genetic conditions or severity of cardiac lesion (e.g., trisomy 21, hypoplastic left heart syndrome) $(109,115)$. In addition, implementation of genetic technologies such as NIPT has not led to an increase in termination rates for aneuploidy as was previously feared $(116,117)$. Continuing ethical dialogue and education of families and clinicians will be essential as we consider the implications of increasing prenatal genetic detection to ensure these findings translate into better patient outcomes and family understanding.

\section{Acknowledgments}

Funding: This work was supported by the Center for Clinical and Translational Sciences, which is funded by National Institutes of Health Clinical and Translational Awards UL1 TR003167 and KL2 TR003168 from the National Center for Advancing Translational Sciences. The content is solely the responsibility of the authors and does not necessarily represent the official views of the National Center for Advancing Translational Sciences or the National Institutes of Health.

\section{Footnote}

Provenance and Peer Review: This article was commissioned by the Guest Editor (Antonio F. Corno) for the series "Pre- natal Diagnosis in Congenital Heart Defects" published in Translational Pediatrics. The article has undergone external peer review.

Conflicts of Interest: Both authors have completed the ICMJE uniform disclosure form (available at http://dx.doi. org/10.21037/tp-20-315). The series "Pre-natal Diagnosis in Congenital Heart Defects" was commissioned by the editorial office without any funding or sponsorship. The authors have no other conflicts of interest to declare.

Ethical Statement: The authors are accountable for all aspects of the work in ensuring that questions related to the accuracy or integrity of any part of the work are appropriately investigated and resolved.

Open Access Statement: This is an Open Access article distributed in accordance with the Creative Commons Attribution-NonCommercial-NoDerivs 4.0 International License (CC BY-NC-ND 4.0), which permits the noncommercial replication and distribution of the article with the strict proviso that no changes or edits are made and the original work is properly cited (including links to both the formal publication through the relevant DOI and the license). See: https://creativecommons.org/licenses/by-nc-nd/4.0/.

\section{References}

1. Friedberg MK, Silverman NH, Moon-Grady AJ, et al. Prenatal detection of congenital heart disease. J Pediatr 2009;155:26-31, 31.e1.

2. Carvalho JS, Mavrides E, Shinebourne EA, et al. Improving the effectiveness of routine prenatal screening for major congenital heart defects. Heart 2002;88:387-91.

3. Liu Y, Chen S, Zühlke L, et al. Global birth prevalence of congenital heart defects 1970-2017: updated systematic review and meta-analysis of 260 studies. Int J Epidemiol 2019;48:455-63.

4. van der Linde D, Konings EE, Slager MA, et al. Birth prevalence of congenital heart disease worldwide: a systematic review and meta-analysis. J Am Coll Cardiol 2011;58:2241-7.

5. Botto LD, Lin AE, Riehle-Colarusso T, et al. Seeking causes: Classifying and evaluating congenital heart defects in etiologic studies. Birth Defects Res A Clin Mol Teratol 2007;79:714-27.

6. Costain G, Silversides CK, Bassett AS. The importance 
of copy number variation in congenital heart disease. NPJ Genom Med 2016;1:16031.

7. Wong SF, Chan FY, Cincotta RB, et al. Factors influencing the prenatal detection of structural congenital heart diseases. Ultrasound Obstet Gynecol 2003;21:19-25.

8. Pinto NM, Keenan HT, Minich LL, et al. Barriers to prenatal detection of congenital heart disease: a population-based study. Ultrasound Obstet Gynecol 2012;40:418-25.

9. Driscoll DA, Gross SJ. Screening for fetal aneuploidy and neural tube defects. Genet Med 2009;11:818-21.

10. Rose NC, Kaimal AJ, Dugoff L, et al. Screening for Fetal Chromosomal Abnormalities: ACOG Practice Bulletin, Number 226. Obstet Gynecol 2020;136:e48-e69.

11. Malone FD, Canick JA, Ball RH, et al. First-trimester or second-trimester screening, or both, for Down's syndrome. N Engl J Med 2005;353:2001-11.

12. Wapner R, Thom E, Simpson JL, et al. First-trimester screening for trisomies 21 and 18. N Engl J Med 2003;349:1405-13.

13. Simpson LL, Malone FD, Bianchi DW, et al. Nuchal translucency and the risk of congenital heart disease. Obstet Gynecol 2007;109:376-83.

14. ACOG Committee on Practice Bulletins. ACOG Practice Bulletin No. 77: screening for fetal chromosomal abnormalities. Obstet Gynecol 2007;109:217-27.

15. Jelliffe-Pawlowski LL, Norton ME, Shaw GM, et al. Risk of critical congenital heart defects by nuchal translucency norms. Am J Obstet Gynecol 2015;212:518.e1-10.

16. Tjoa ML, Cindrova-Davies T, Spasic-Boskovic O, et al. Trophoblastic oxidative stress and the release of cell-free feto-placental DNA. Am J Pathol 2006;169:400-4.

17. Ehrich M, Deciu C, Zwiefelhofer T, et al. Noninvasive detection of fetal trisomy 21 by sequencing of DNA in maternal blood: a study in a clinical setting. Am J Obstet Gynecol 2011;204:205.e1-11.

18. Bianchi DW, Platt LD, Goldberg JD, et al. Genomewide fetal aneuploidy detection by maternal plasma DNA sequencing. Obstet Gynecol 2012;119:890-901.

19. Norton ME, Brar H, Weiss J, et al. Non-Invasive Chromosomal Evaluation (NICE) Study: results of a multicenter prospective cohort study for detection of fetal trisomy 21 and trisomy 18. Am J Obstet Gynecol 2012;207:137.e1-8.

20. Nicolaides KH, Syngelaki A, Ashoor G, et al. Noninvasive prenatal testing for fetal trisomies in a routinely screened first-trimester population. Am J Obstet Gynecol 2012;207:374.e1-6.

21. Bianchi DW, Parker RL, Wentworth J, et al. DNA sequencing versus standard prenatal aneuploidy screening. N Engl J Med 2014;370:799-808.

22. Norton ME, Jacobsson B, Swamy GK, et al. Cell-free DNA analysis for noninvasive examination of trisomy. $\mathrm{N}$ Engl J Med 2015;372:1589-97.

23. Taylor-Phillips S, Freeman K, Geppert J, et al. Accuracy of non-invasive prenatal testing using cell-free DNA for detection of Down, Edwards and Patau syndromes: a systematic review and meta-analysis. BMJ Open 2016;6:e010002.

24. Badeau M, Lindsay C, Blais J, et al. Genomics-based noninvasive prenatal testing for detection of fetal chromosomal aneuploidy in pregnant women. Cochrane Database Syst Rev 2017;11:CD011767.

25. Coalition for Access to Prenatal Screening. Available online: https://capsprenatal.com/coverage-scorecards [Accessedt 21, 2020].

26. Gregg AR, Skotko BG, Benkendorf JL, et al. Noninvasive prenatal screening for fetal aneuploidy, 2016 update: a position statement of the American College of Medical Genetics and Genomics. Genet Med 2016;18:1056-65.

27. Bianchi DW, Chudova D, Sehnert AJ, et al. Noninvasive Prenatal Testing and Incidental Detection of Occult Maternal Malignancies. JAMA 2015;314:162-9.

28. Brady P, Brison N, Van Den Bogaert K, et al. Clinical implementation of NIPT - technical and biological challenges. Clin Genet 2016;89:523-30.

29. Kornman L, Palma-Dias R, Nisbet D, et al. NonInvasive Prenatal Testing for Sex Chromosome Aneuploidy in Routine Clinical Practice. Fetal Diagn Ther 2018;44:85-90.

30. Zhang B, Lu BY, Yu B, et al. Noninvasive prenatal screening for fetal common sex chromosome aneuploidies from maternal blood. J Int Med Res 2017;45:621-30.

31. Norton ME, Rose NC, Benn P. Noninvasive prenatal testing for fetal aneuploidy: clinical assessment and a plea for restraint. Obstet Gynecol 2013;121:847-50.

32. Dondorp W, de Wert G, Bombard Y, et al. Non-invasive prenatal testing for aneuploidy and beyond: challenges of responsible innovation in prenatal screening. Eur J Hum Genet 2015;23:1438-50.

33. Salomon LJ, Sotiriadis A, Wulff CB, et al. Risk of miscarriage following amniocentesis or chorionic villus sampling: systematic review of literature and updated meta-analysis. Ultrasound Obstet Gynecol 2019;54:442- 
451. doi: 10.1002/uog.20353. Epub 2019 6. PMID: 31124209.

34. Fang YM, Benn P, Campbell W, et al. Down syndrome screening in the United States in 2001 and 2007: a survey of maternal-fetal medicine specialists. Am J Obstet Gynecol 2009;201:97.e1-5.

35. Nakata N, Wang Y, Bhatt S. Trends in prenatal screening and diagnostic testing among women referred for advanced maternal age. Prenat Diagn 2010;30:198-206.

36. American College of Obstetricians and Gynecologists' Committee on Practice Bulletins-Obstetrics; Committee on Genetics; Society for Maternal-Fetal Medicine. Practice Bulletin No. 162: Prenatal Diagnostic Testing for Genetic Disorders. Obstet Gynecol 2016;127:e108-22.

37. Rayburn WF, Jolley JA, Simpson LL. Advances in ultrasound imaging for congenital malformations during early gestation. Birth Defects Res A Clin Mol Teratol 2015;103:260-8.

38. Rossi AC, Prefumo F. Accuracy of ultrasonography at 11-14 weeks of gestation for detection of fetal structural anomalies: a systematic review. Obstet Gynecol 2013;122:1160-7.

39. Whitworth M, Bricker L, Mullan C. Ultrasound for fetal assessment in early pregnancy. Cochrane Database Syst Rev 2015 14;2015:CD007058.

40. Pinto NM, Keenan HT, Minich LL, et al. Barriers to prenatal detection of congenital heart disease: a population-based study. Ultrasound Obstet Gynecol 2012;40:418-25.

41. Edwards L, Hui L. First and second trimester screening for fetal structural anomalies. Semin Fetal Neonatal Med 2018;23:102-11.

42. Nyberg DA, Souter VL. Sonographic markers of fetal trisomies: second trimester. J Ultrasound Med 2001;20:655-74.

43. Viora E, Zamboni C, Mortara G, et al. Trisomy 18: Fetal ultrasound findings at different gestational ages. Am J Med Genet A 2007;143A:553-7.

44. Benacerraf BR. The history of the second-trimester sonographic markers for detecting fetal Down syndrome, and their current role in obstetric practice. Prenat Diagn 2010;30:644-52.

45. Aagaard-Tillery KM, Malone FD, Nyberg DA, et al.; First and Second Trimester Evaluation of Risk Research Consortium. Role of second-trimester genetic sonography after Down syndrome screening. Obstet Gynecol 2009;114:1189-96.
46. Salomon LJ, Alfirevic Z, Audibert F, et al. ISUOG consensus statement on the impact of non-invasive prenatal testing (NIPT) on prenatal ultrasound practice. Ultrasound Obstet Gynecol 2014;44:122-3.

47. Beulen L, Faas BHW, Feenstra I, et al. Clinical utility of non-invasive prenatal testing in pregnancies with ultrasound anomalies. Ultrasound Obstet Gynecol 2017;49:721-8.

48. Evans PR. Cardiac anomalies in mongolism. Br Heart J 1950;12:258-62.

49. Lejeune J, Turpin R, Gautier M. Chromosomic diagnosis of mongolism. Arch Fr Pediatr 1959;16:962-3.

50. Geng J, Picker J, Zheng Z, et al. Chromosome microarray testing for patients with congenital heart defects revealsel disease causing loci and high diagnostic yield. BMC Genomics 2014 17;15:1127.

51. Pierpont ME, Brueckner M, Chung WK, et al. Genetic Basis for Congenital Heart Disease: Revisited: A Scientific Statement From the American Heart Association. Circulation 2018;138:e653-e711.

52. Hartman RJ, Rasmussen SA, Botto LD, et al. The contribution of chromosomal abnormalities to congenital heart defects: a population-based study. Pediatr Cardiol 2011;32:1147-57.

53. Zaidi S, Brueckner M. Genetics and genomics of congenital heart disease. Circ Res 2017;120:923-40.

54. Øyen N, Poulsen G, Boyd HA, et al. Recurrence of congenital heart defects in families. Circulation 2009;120:295-301.

55. Shieh JT, Bittles AH, Hudgins L. Consanguinity and the risk of congenital heart disease. Am J Med Genet A 2012;158A:1236-41.

56. Jin SC, Homsy J, Zaidi S, et al. Contribution of rare inherited and deo variants in 2,871 congenital heart disease probands. Nat Genet 2017;49:1593-601.

57. Unolt $M$, Versacci $P$, Anaclerio S, et al. Congenital heart diseases and cardiovascular abnormalities in $22 \mathrm{q} 11.2$ deletion syndrome: From well-established knowledge to new frontiers. Am J Med Genet A 2018;176:2087-98.

58. Fung A, Manlhiot C, Naik S, et al. Impact of prenatal risk factors on congenital heart disease in the current era. J Am Heart Assoc 2013 31;2:e000064.

59. Bull MJ. Down syndrome. N Engl J Med 2020;382:2344-52.

60. Ranke MB, Saenger P. Turner's syndrome. Lancet 2001;358:309-14.

61. Hook EB, Warburton D. The distribution of chromosomal 
genotypes associated with Turner's syndrome: livebirth prevalence rates and evidence for diminished fetal mortality and severity in genotypes associated with structural X abnormalities or mosaicism. Hum Genet 1983;64:24-7.

62. Wolff DJ, Van Dyke DL, Powell CM. Laboratory guideline for Turner syndrome. Genet Med 2010;12:52-5.

63. Ruiz C, Lamm F, Hart PS. Turner syndrome and multiplemarker screening. Clin Chem 1999;45:2259-61.

64. Gil MM, Quezada MS, Revello R, et al. Analysis of cell-free DNA in maternal blood in screening for fetal aneuploidies: updated meta-analysis. Ultrasound Obstet Gynecol 2015;45:249-66.

65. Russell LM, Strike P, Browne CE, et al. X chromosome loss and ageing. Cytogenet Genome Res 2007;116:181-5.

66. Zarrei M, MacDonald JR, Merico D, et al. A copy number variation map of the human genome. Nat Rev Genet 2015;16:172-83.

67. Fruhman G, Van den Veyver IB. Applications of array comparative genomic hybridization in obstetrics. Obstet Gynecol Clin North Am 2010;37:71-85, Table of Contents.

68. Poirsier C, Besseau-Ayasse J, Schluth-Bolard C, et al. A French multicenter study of over 700 patients with $22 q 11$ deletions diagnosed using FISH or aCGH. Eur J Hum Genet 2016;24:844-51.

69. Zhao Y, Diacou A, Johnston HR, et al. Complete Sequence of the 22q11.2 Allele in 1,053 Subjects with 22q11.2 Deletion Syndrome Reveals Modifiers of Conotruncal Heart Defects. Am J Hum Genet 2020;106:26-40.

70. Botto LD, K, Fernhoff PM, et al. A population-based study of the 22 q11.2 deletion: phenotype, incidence, and contribution to major birth defects in the population. Pediatrics 2003;112:101-7.

71. Oneda B, Rauch A. Microarrays in prenatal diagnosis. Best Pract Res Clin Obstet Gynaecol 2017;42:53-63.

72. Miller DT, Adam MP, Aradhya S, et al. Consensus statement: chromosomal microarray is a first-tier clinical diagnostic test for individuals with developmental disabilities or congenital anomalies. Am J Hum Genet 2010;86:749-64.

73. South ST, Lee C, Lamb AN, et al. ACMG Standards and Guidelines for constitutional cytogenomic microarray analysis, including postnatal and prenatal applications: revision 2013. Genet Med 2013;15:901-9.

74. Jansen FA, Blumenfeld YJ, Fisher A, et al. Array comparative genomic hybridization and fetal congenital heart defects: a systematic review and meta-analysis.
Ultrasound Obstet Gynecol 2015;45:27-35.

75. Waggoner D, Wain KE, Dubuc AM, et al. Yield of additional genetic testing after chromosomal microarray for diagnosis of neurodevelopmental disability and congenital anomalies: a clinical practice resource of the American College of Medical Genetics and Genomics (ACMG). Genet Med 2018;20:1105-13.

76. Richards S, Aziz N, Bale S, et al. Standards and guidelines for the interpretation of sequence variants: a joint consensus recommendation of the American College of Medical Genetics and Genomics and the Association for Molecular Pathology. Genet Med 2015;17:405-24.

77. Riggs ER, Andersen EF, Cherry AM, et al. Technical standards for the interpretation and reporting of constitutional copy-number variants: a joint consensus recommendation of the American College of Medical Genetics and Genomics (ACMG) and the Clinical Genome Resource (ClinGen). Genet Med 2020;22:245-57.

78. Manning M, Hudgins L. Array-based technology and recommendations for utilization in medical genetics practice for detection of chromosomal abnormalities. Genet Med 2010;12:742-5.

79. Shaffer LG, Rosenfeld JA, Dabell MP, et al. Detection rates of clinically significant genomic alterations by microarray analysis for specific anomalies detected by ultrasound. Prenat Diagn 2012;32:986-95.

80. Lee CN, Lin SY, Lin CH, et al. Clinical utility of array comparative genomic hybridisation for prenatal diagnosis: a cohort study of 3171 pregnancies. BJOG 2012;119:614-25.

81. Donnelly JC, Platt LD, Rebarber A, et al. Association of copy number variants with specific ultrasonographically detected fetal anomalies. Obstet Gynecol 2014;124:83-90.

82. Sagi-Dain L, Maya I, Reches A, et al. Chromosomal Microarray Analysis Results From Pregnancies With Various Ultrasonographic Anomalies. Obstet Gynecol 2018;132:1368-75.

83. Wang Y, Cao L, Liang D, et al. Prenatal chromosomal microarray analysis in fetuses with congenital heart disease: a prospective cohort study. Am J Obstet Gynecol 2018;218:244.e1-244.e17.

84. Xia Y, Yang Y, Huang S, et al. Clinical application of chromosomal microarray analysis for the prenatal diagnosis of chromosomal abnormalities and copy number variations in fetuses with congenital heart disease. Prenat Diagn 2018;38:406-13.

85. Zhu X, Li J, Ru T, et al. Identification of copy number variations associated with congenital heart disease by chromosomal microarray analysis and next-generation 
sequencing. Prenat Diagn 2016;36:321-7.

86. Liao C, Li R, Fu F, et al. Prenatal diagnosis of congenital heart defect by genome-wide high-resolution SNP array. Prenat Diagn 2014;34:858-63.

87. Yan $\mathrm{Y}, \mathrm{Wu} \mathrm{Q}$, Zhang L, et al. Detection of submicroscopic chromosomal aberrations by array-based comparative genomic hybridization in fetuses with congenital heart disease. Ultrasound Obstet Gynecol 2014;43:404-12.

88. Song T, Wan S, Li Y, et al. Detection of copy number variants using chromosomal microarray analysis for the prenatal diagnosis of congenital heart defects with normal karyotype. J Clin Lab Anal 2019;33:e22630.

89. Turan S, Asoglu MR, Gabbay-Benziv R, et al. Yield rate of chromosomal microarray analysis in fetuses with congenital heart defects. Eur J Obstet Gynecol Reprod Biol 2018;221:172-6.

90. van Nisselrooij AEL, Lugthart MA, Clur SA, et al. The prevalence of genetic diagnoses in fetuses with severe congenital heart defects. Genet Med 2020;22:1206-14.

91. Carey AS, Liang L, Edwards J, et al. Effect of copy number variants on outcomes for infants with single ventricle heart defects. Circ Cardiovasc Genet 2013;6:444-51.

92. Kim DS, Kim JH, Burt AA, et al. Burden of potentially pathologic copy number variants is higher in children with isolated congenital heart disease and significantly impairs covariate-adjusted transplant-free survival. J Thorac Cardiovasc Surg 2016;151:1147-51.e4.

93. De Groote K, Vanhie E, Roets E, et al. Outcome after prenatal and postnatal diagnosis of complex congenital heart defects and the influence of genetic anomalies. Prenat Diagn 2017;37:983-91.

94. Croonen EA, Nillesen WM, Stuurman KE, et al. Prenatal diagnostic testing of the Noonan syndrome genes in fetuses with abnormal ultrasound findings. Eur J Hum Genet 2013;21:936-42.

95. Tartaglia M, Kalidas K, Shaw A, et al. PTPN11 mutations in Noonan syndrome: molecular spectrum, genotypephenotype correlation, and phenotypic heterogeneity. Am J Hum Genet 2002;70:1555-63.

96. Pandit B, Sarkozy A, Pennacchio LA, et al. Gain-offunction RAF1 mutations cause Noonan and LEOPARD syndromes with hypertrophic cardiomyopathy. Nat Genet 2007;39:1007-12.

97. Myers A, Bernstein JA, Brennan ML, et al. Perinatal features of the RASopathies: Noonan syndrome, cardiofaciocutaneous syndrome and Costello syndrome. Am J Med Genet A 2014;164A:2814-21.

98. Ali MM, Chasen ST, Norton ME. Testing for Noonan syndrome after increased nuchal translucency. Prenat Diagn 2017;37:750-3.

99. Hakami F, Dillon MW, Lebo M, et al. Retrospective study of prenatal ultrasound findings in newborns with a Noonan spectrum disorder. Prenat Diagn 2016;36:418-23.

100. Baldassarre G, Mussa A, Dotta A, et al. Prenatal features of Noonan syndrome: prevalence and prognostic value. Prenat Diagn 2011;31:949-54.

101. Behjati S, Tarpey PS. What is next generation sequencing? Arch Dis Child Educ Pract Ed 2013;98:236-8.

102.Hu P, Qiao F, Wang Y, et al. Clinical application of targeted next-generation sequencing in fetuses with congenital heart defect. Ultrasound Obstet Gynecol 2018;52:205-11.

103.Petrovski S, Aggarwal V, Giordano JL, et al. Whole-exome sequencing in the evaluation of fetal structural anomalies: a prospective cohort study. Lancet 2019;393:758-767.

104.Lord J, McMullan DJ, Eberhardt RY, et al. Prenatal exome sequencing analysis in fetal structural anomalies detected by ultrasonography (PAGE): a cohort study. Lancet 2019;393:747-57.

105. Brew CE, Castro BA, Pan V, et al. Genetics professionals' attitudes toward prenatal exome sequencing. J Genet Couns 2019;28:229-39.

106. Carlsson T, Bergman G, Melander Marttala U, et al. Information following a diagnosis of congenital heart defect: experiences among parents to prenatally diagnosed children. PLoS One 2015;10:e0117995.

107. Rychik J, Donaghue DD, Levy S, et al. Maternal psychological stress after prenatal diagnosis of congenital heart disease. J Pediatr 2013;162:302-7.e1.

108.Zyblewski SC, Hill EG, Shirali G, et al. Chromosomal anomalies influence parental treatmentisions in relation to prenatally diagnosed congenital heart disease. Pediatr Cardiol 2009;30:1105-11.

109. Stoll C, Alembik Y, Dott B, et al. Impact of prenatal diagnosis on livebirth prevalence of children with congenital anomalies. Ann Genet 2002;45:115-21.

110. Meyer RE, Liu G, Gilboa SM, et al. Survival of children with trisomy 13 and trisomy 18: A multi-state populationbased study. Am J Med Genet A 2016;170A:825-37.

111. Cooper DS, Riggs KW, Zafar F, et al. Cardiac Surgery in Patients With Trisomy 13 and 18: An Analysis of The Society of Thoracic Surgeons Congenital Heart Surgery Database. J Am Heart Assoc 2019;8:e012349.

112. Carvajal HG, Callahan CP, Miller JR, et al. Cardiac Surgery in Trisomy 13 and 18: A Guide to ClinicalisionMaking. Pediatr Cardiol 2020;41:1319-33. 
113. Corno AF. Ethical issues after pre-natal diagnosis. Transl Pediatr 2020. doi: 10.21037/tp-20-141

114. Kovacevic A, Elsässer M, Fluhr H, et al. Counseling for fetal heart disease-current standards and best practice. Transl Pediatr 2020. doi: 10.21037/tp-20-181.

115. Gaynor JW, Stopp C, Wypij D, et al. Neurodevelopmental outcomes after cardiac surgery in infancy. Pediatrics 2015;135:816-25.

Cite this article as: Findley TO, Northrup H. The current state of prenatal detection of genetic conditions in congenital heart defects. Transl Pediatr 2021;10(8):2157-2170. doi: $10.21037 /$ tp-20-315
116. Hill M, Barrett A, Choolani M, et al. Has noninvasive prenatal testing impacted termination of pregnancy and live birth rates of infants with Down syndrome? Prenat Diagn 2017;37:1281-90.

117. Reiss RE, Discenza M, Foster J, et al. Sex chromosome aneuploidy detection by noninvasive prenatal testing: helpful or hazardous? Prenat Diagn 2017;37:515-20. 